\title{
Analysis of single-cell RNA-sequencing data to identify quiescent and proliferating neural cell populations in Glioblastoma
}

(1)

$$
\text { Rajeev Vikram }{ }^{*} \text {, Wen } \square \text { Cheng } \text { Chou }^{1} \text {, Pei-Ei Wu }{ }^{1} \text {, Wei-Ting Chen }{ }^{1} \text {, Chen-Yang Shen }{ }^{* 1,2}
$$

${ }^{1}$ Institute of Biomedical Sciences, Taipei 115, Taiwan, ${ }^{2}$ Graduate Institute of Environmental Science, China Medical University, Taichung 404, Taiwan

*corresponding authors: rajeev.vkrm@ibms.sinica.edu.tw, bmcys@ibms.sinica.edu.tw

7

\section{ABSTRACT}

\section{Background:}

Diffuse Glioblastoma (GBM) has high mortality and remains one of the most challenging type of cancer to treat. Identifying and characterizing the cells populations driving tumor growth and therapy resistance has been particularly difficult owing to marked inter and intra tumoral heterogeneity observed in these tumors. These tumorigenic populations contain long lived cells associated with latency, immune evasion and metastasis.

\section{Methods:}

Here, we analyzed the single-cell RNA-sequencing data of high grade glioblastomas from four different studies using integrated analysis of gene expression patterns, cell cycle stages and copy number variation to identify gene expression signatures associated with quiescent and cycling neuronal tumorigenic cells.

\section{Results:}

The results show that while cycling and quiescent cells are present in GBM of all age groups, they exist in a much larger proportion in pediatric glioblastomas. These cells show similarities in 
22 their expression patterns of a number of pluripotency and proliferation related genes. Upon

23 unbiased clustering, these cells explicitly clustered on their cell cycle stage. Quiescent cells in

24 both the groups specifically overexpressed a number of genes for ribosomal protein, while the

25 cycling cells were enriched in the expression of high-mobility group and heterogeneous nuclear

26 ribonucleoprotein group genes. A number of well-known markers of quiescence and proliferation

27 in neurogenesis showed preferential expression in the quiescent and cycling populations

28 identified in our analysis. Through our analysis, we identify ribosomal proteins as key

29 constituents of quiescence in glioblastoma stem cells.

30 Conclusions:

31 This study identifies gene signatures common to adult and pediatric glioblastoma quiescent and 32 cycling stem cell niches. Further research elucidating their role in controlling quiescence and 33 proliferation in tumorigenic cells in high grade glioblastoma will open avenues in more effective 34 treatment strategies for glioblastoma patients. 
44 Diffuse gliomas are tumors of the central nervous system with histological similarity to glial cells. Worldwide, approximately 100,000 new cases of diffuse glioma are reported every year[1]. Despite it being a relatively rare cancer type, diffuse gliomas have a very poor prognosis with high mortality burden. The 2016 WHO classification of gliomas divides them into astrocytomas, oligodendrogliomas and oligoastrocytomas with subgroupings based on IDH mutations and 1p19q co-deletion status[2]. Irrespective of the categories, the tumors are graded from one to four according to the histological degree of malignancy.

The grade IV diffuse astrocytoma (IDH-wildtype) also called as glioblastoma (GBM) accounts for about $75 \%$ of all diffuse gliomas with a median survival of about one to two years after therapy, making it the most lethal of gliomas[2,3]. Intratumoral heterogeneity in GBM is a key challenge to developing effective therapeutic strategies. Neurodevelopmental bi-lineage hierarchy does partially explain the heterogeneity in IDH-mutant and pediatric gliomas, however, this bi-lineage hierarchy model fails to explain the widespread phenotypic heterogeneity and evolving phenotypic states in GBM. The cancer stem cells (CSC) theory suggests that Glioblastoma Stem-like Cells (GSCs) are at the center of the tumor organization and instrumental in generating and replicating intratumoral phenotypic heterogeneity[4]. Indeed, similar to other cancers, intratumoral heterogeneity, resistance to treatment and relapse in GBM has been attribute to this small subpopulation in a number of studies. Although GSCs seem to be a key target in GBM therapy, their existence and cellular nature remains a hotly debated topic. While there is evidence pointing to the presence of such GSCs, identification of these cells has remained a challenge. Primarily because there is no marker which can be considered to universally identify GSCs[5]. 
In most cancers including GBM, single surface marker approach has been used to identify

67 CGSCs. A number of cell membrane antigens like CD133, CD15/SSEA, CD44, PDGFRA,

68

69 EGFR or A2B5 are shown to be associated with potential GSCs. Earlier studies showing the tumorigenic potential of cells isolated using one or a combination of these markers [6-11] did not address the tumorigenic potential of marker negative cells. Later studies however show that both the marker positive and negative glioma fractions can show multipotent behavior $[8,12]$. Recent reports show that marker negative cells are able to generate marker positive cells and replicate the tumor heterogeneity[13]. Thus the evidence so far indicates a non-hierarchical model where cells niches with strong cellular plasticity are at the core of recreating intratumoral heterogeneity. Evidence supporting intratumoral cell niches with high cellular plasticity in glioblastoma comes from a recent study by Jung, Erik, et al.[14]. The authors show the existence two complementary cellular niches driving tumor progression and therapy resistance in GBM. Further evidence of the plastic nature of GSC niches come from studies which demonstrate the generation of potential GSCs from non-tumorigenic glioma cells [15]. Based on these and a number of other recent studies, it seems that within the tumor, potential GSCs remain in interactive niches and are highly plastic in addition to being able to acquire therapy resistance and tumorigenicity. Recent studies in tumor immunosurveillance evasion suggests that these niches are composed of small populations of cycling and quiescent stem cell like cells [16].

Advances in newer methods to study cellular transcriptomes at the single cell level especially massively parallel single-cell RNA-sequencing (scRNAseq) has significantly enhanced our understanding of spatial and temporal heterogeneity in glioblastoma. Recent single cell studies of gliomas have shown the presence of a progenitor type population [17-19]. Interestingly, in terms of conventional markers, tumors from different patients show variability in their expression, 
suggesting heterogeneity within GSCs[20]. As more and more genomic and transcriptomic data from single cell experiments in gliomas becomes available, it is becoming more evident that although canonical GSC markers seem to be associated with proliferative cells in low grade gliomas, such correlation is not evident in GBM[21]. Thus, projects designed to identify GSCs on the hierarchical CGSC model have largely been ineffective.

To develop a better diagnostic and treatment strategy for GBM as well as low grade glioma, is it important understand the dynamics of the tumor microenvironment, especially the intrinsic plasticity of the cell niches. Understanding the mechanism of maintenance of these highly plastic cell subpopulations within the tumor, the role of the microenvironment dynamics in selection and survival of such populations and their propagation are instrumental in unearthing the reasons for the development of resistance to Temozolomide (TMZ) chemotherapy and radiotherapy.

A number of recent studies have utilized scRNAseq to study gliomas of different origin and grade generating a wealth of data on the transcriptomic nature of cells within the tumor[14, 17, $19,22]$. While these studies primarily focused on different states of gliomas and tumor-immune cell interaction, few studies have tried to delineate differences in cellular states within neural cells in GBM. Reanalysis of these scRNA-seq datasets can give us a deeper understanding of the genomic and transcriptomic commonalities within malignant neural subpopulations. Identification of GSC niches with quiescent population perhaps holds and the key to developing strategies which can target genes/transcripts involved in maintaining GSC plasticity and crosstalk in high grade gliomas.

Here, we analyze the scRNAseq data from four different studies encompassing thousands of tumor and peripheral cells from pediatric and adult IDH-wildtype glioblastoma patients to identify and study quiescent and cycling GSCs. The tumor types range from primary to relapsed 
112 tumors. Our results show that cycling and quiescent like-cell subpopulation are present in most

113 GBM tumors with a gene expression signature associated with ribosomal biogenesis, cell cycle

114 activation and malignancy. Key overexpressed genes include DCX, SOX4 and DLL3, known

115 markers for quiescence, stemness and tumorigenicity. These cells have a Copy number variance

116 pattern distinguishing them from other neural cells subtypes within the tumor. and key

117 genes/transcripts expression pattern in these niches across GBM tumor types. 


\section{Selection of datasets and identification of neural cells}

138 To identify common GSC like populations across GBMs, we selected scRNAseq datasets from 139 different studies representing IDH-wildtype, grade IV glioblastomas. Included datasets represent 140 major patient groups (pediatric, adult and recurrent). Table 1 shows the major characteristics of 141 the included datasets. For differential gene expression analysis of GBM subpopulations, we also 142 included brain metastasis (lung squamous cell carcinoma) data set from the study GSE117891.

\section{Table 1 Dataset Summary}

\begin{tabular}{|c|c|c|c|c|c|}
\hline Dataset & $\begin{array}{l}\text { No. of } \\
\text { Cells }\end{array}$ & Location & $\begin{array}{l}\text { No. of } \\
\text { Patients }\end{array}$ & Tumor Type & Tumor Grade \\
\hline GSE84465 & 1745 & Tumor/Periphery & 4 & Primary & IDH-wildtype \\
\hline GSE131928 & 1460 & Tumor & 6 & $\begin{array}{l}\text { Primary/ } \\
\text { Recurrent }\end{array}$ & IDH-wildtype \\
\hline GSE103224 & 3679 & Tumor & 2 & Recurrent & IDH-wildtype \\
\hline GSE117891 & 359 & Tumor/Periphery & 1 & $\begin{array}{l}\text { Metastatic (Lung } \\
\text { Squamous Cell } \\
\text { Carcinoma) }\end{array}$ & NA \\
\hline
\end{tabular}


145 Significant inter and intratumoral heterogeneity is a challenge in identifying GSC like niches

146 because gene expression patterns of different cell types and sample origin (i.e., transcriptomic

147 diversity of the samples) induce strong variance which often masks the similarities in cellular

148 programs in small subpopulations. Malignant cells with stem cell like properties are typically a

149 very small subset of the tumor population. We therefore first sought to enrich our datasets based

150 on clear cell identity and malignancy. The datasets were first clustered using the standard Seurat-

151 sctarnsform pipeline. As, GBMs primarily originate in neural cells, we first identified the clusters

152 of clear neural/glial (neuronal) or myeloid/immune origin by measuring the expression of known

153 markers for immune cells (CD4, CD83\& \&LA-DRA) and neuronal cells (S100B, OLIG1 \&

154 SCG2) [23, 24] (Figure 1 B, C). Clusters are represented using Uniform Manifold

155 Approximation and Projection (UMAP) (Figure 1A). The neuronal cluster significantly

156 overexpressed EGFR, a gene overexpressed in $30-50 \%$ of all GBMs and associated with

157 neoplasia. Interestingly, non-GBM tumor cells (GSE117891) did not express EGFR and showed

158 markedly different non myeloid/immune cluster profile. (Figure 1D). These clusters showed

159 distinct expression profiles for glial cell markers for astrocyte(S100B) and

160 oligodendrocytes(OLIG2). Indicating the presence of transformed non neural cells in these

161 clusters (Figure $1 \mathrm{~B}, \mathrm{C})$. 


\begin{tabular}{|c|c|c|c|c|}
\hline Group & Source & Patient-ID & $\begin{array}{l}\text { Molecular } \\
\text { Subtype }\end{array}$ & $\begin{array}{l}\text { No. of } \\
\text { Transformed } \\
\text { Cells }\end{array}$ \\
\hline \multirow{7}{*}{ Adult } & \multirow[t]{4}{*}{ GSE84465 } & BT-S1 & Classical & 351 \\
\hline & & BT-S2 & Classical & 713 \\
\hline & & BT-S4 & Classical & 367 \\
\hline & & BT-S6 & Proneural & 143 \\
\hline & \multirow[t]{2}{*}{ GSE103224 } & PJ-32 & Mesenchymal & 574 \\
\hline & & PJ-35 & Classical & 3105 \\
\hline & GSE117891 & GS-15 & NA & 352 \\
\hline \multirow{7}{*}{ Pediatric } & \multirow{7}{*}{ GSE131928 } & BT-749 & Proneural & 253 \\
\hline & & BT-771 & Mesenchymal & 256 \\
\hline & & BT-786 & Proneural & 160 \\
\hline & & BT-830 & Mesenchymal & 166 \\
\hline & & BT-920 & Mesenchymal & 07 \\
\hline & & BT-1160 & Proneural & 332 \\
\hline & & MGH-85 & Proneural & 245 \\
\hline
\end{tabular}

168 To identify malignant or transformed stem-like cells, we decided to focus exclusively on 169 neuronal cells and examine them in detail. To do so, we first removed the immune/myeloid 170 clusters from the study. Next, we used the mutual nearest neighbors (MNNs) method in 171 conjugation with Seurat to integrate the datasets. For comparative analysis, we created two 
172 integrated datasets comprising of adult and pediatric GBM patients. Table 2 shows the patient

173 wise detail of the adult and pediatric groups. Both adult and pediatric groups clustered largely

174 according to cell types and cell stages (figure 2 A, B). Comparison of adult and pediatric groups

175 showed that a number of genes specific to cell cycle, neuronal and glial cells like TOP2A,

177 overexpressed in certain clusters in both the groups. (figure 2 B). Whilst SLC1A2, APOD, PLP1,

178 CD74, and RTN1 are cell type specific proteins and expressed by astrocytes, oligodendrocytes,

179 OPCs and endothelial cells respectively[25], TOP2A and HMGB2 expression is specific to

180

181

182

183

184

185

186

187

188

189

190

191

192

193

194

transcriptional activation and cell cycle[26, 27]. CHI3L1 and SERPINE1 are both proteins

related to cell differentiation and malignant transformation[28, 29]. Comparatively, Adult GBM dataset exhibited greater number of distinct clusters which might be reflective of higher cell type and disease stage diversity. The presence of specific clusters overexpressing TOP2A and SOX4 in both adult and pediatric groups indicated a similarity in gene expression profile of these clusters across groups. Cycling or actively dividing and quiescent stem cells are known to coexist in adult stem cell niches[30]. Hence, we assessed the expression distribution of known markers for proliferation (KI67and CD44) and maintenance of cellular plasticity (SOX11 and DCX). The expression of these genes coincided with clusters 1,2 and 3 the adult group while in the pediatric group, all clusters except clusters 3 and 7 showed high expression of these genes (Figure 2 C). Interestingly, CD44 expression did not follow this pattern, its expression was confined to clusters unrelated to the expression of other markers. Indeed, recent reports have questioned the validity of CD44 as a reliable marker of proliferation in glioblastoma [20, 31]. As, TOP2A, MKI67, DCX,SOX4 and SOX11 genes are known to show high expression in cycling and Quiescent stem cells respectively[26, 32], we suspected the presence of similar niches within 
195

196

197

198

199

200

201

202

203

204

205

206

207

208

209

210

211

212

213

214

215

216

217

the above mentioned clusters in the GBM groups. To verify this hypothesis, we decided to further analyze the cell type context of these clusters. Top 50 differentially expressed genes for both adult and pediatric groups are included in additional file 1.

\section{Identification of types and cell cycle stages}

To determine the presence of cycling and Quiescent cells in both groups, we sought to identify and distinguish these cells from mature neural and glial cells. We used single cell datasets of adult and embryonic brain, from Darmanis, Spyros, et al.[25] as reference dataset and performed unbiased cell type recognition using SingleR package (see methods). The parameters used are described in the methods section. The results confirmed the initial clustering based predictions and showed the presence of both cycling stem cell like (cGSC) and Quiescent stem cell like (qGSC) cells in patient samples from both groups (Figure 3 A). Comparatively, the proportion of cGSCs and qGSCs was much higher in the pediatric group. Specifically, qGSC population was markedly low in adult group. Patient samples BT-S2 and BT-S4 had no identified qGSCs, while only one cell could be identified as qGSC in PJ-32, while PJ-35 had highest number of both qGSCs and cGSCs in the adult group (Figure $3 \mathrm{D}$ ), probably because a large number of cells in the group are from PJ-35. Expectedly, both these populations were absent in the non-GBM metastatic tumor sample (GS-15), confirming their importance as key originators of GBM.

\section{Analysis of cycling and quiescent cells}

To do a comparative analysis of the gene expression patterns between the groups, differential gene expression analysis was performed using Model-based Analysis of Single Cell Transcriptomics (MAST) package from R. Significant differentially expressed genes for both qGSCs and cGSCs were compared with other cell types in both adult and pediatric groups (figure $3 \mathrm{~B}$ ). In both groups, qGSCs had a markedly high expression of $D C X, S O X 4, S O X 11$ and 
DLL3 genes. While SOX4 and SOX 11 are both critical in the development and maintenance of neural pluripotent cells, DCX is an essential factor in neurogenesis in neuronal migration. DLL3 is a ligand for the Notch pathway and plays a pleotropic role in notch pathway regulation [32]. On the other hand, cGSCs in both groups were marked by overexpression of HMGB2, HSP90B1 and KPNA2 apart from TOP2A (figure $3 \mathrm{C}$ ). HMGB2 is a member of the high mobility protein family, functioning as a modulator of chromatin structure. However, recent study has shown its role in transition from quiescence to activated state in neuronal stem cells (NSCs) [27]. Similarly, HSP90B1, a member of the heat shock protein family, has a role in maintaining embryonic pluripotency [36], whereas KPNA2 is known to be associated with a number of cancers[37]. comparatively, in the adult group, qGSCs and cGSCs have a marked difference in their expression profiles, but less so in the pediatric group. A possible reason for this distinction perhaps is the fact that pediatric brain cells are primed for development.

This is also evident from the cell cycle stage prediction. Previous studies have shown that pluripotency in stem cells is intricately related with cell cycle stages. Whilst a short or truncated G1 (gap1) phase is considered a hallmark of pluripotent state, lengthening of G1 phase is observed when the cells enter cycling phase of rapid differentiation[33-35]. To further confirm the cellular states of these populations, we did a cell cycle state pseudotime prediction using Tricycle $\mathrm{R}$ package as described in the methods section. As, the Quiescent or G0 state is not exclusively defined in continuous cell state pseudotime embedding, we expected to find the qGSC cells to be predicted in the G0/G1 phase range, whilst cGSCs to be in G2/M state range. The results were as expected with qGSC almost exclusively in G0/early G1 state whilst cGSCs in late G1 to M states (Supplementary Figure S1). Interestingly, the distribution of cells within cellular states was continuous showing the presence of cells in intermediate states, indicating a 
transition between qGSC and cGSC states. As, the stem cell like nature of these clusters was supported by both cell type and cell state analysis, we separated these clusters from other cell types and did a comparative analysis of underlying gene expression patterns between adult and pediatric groups to identify universal expression signatures of qGSCs and cGSCs.

\section{Cluster analysis of cycling and quiescent cells}

qGSCs and cGSCs from both groups were reclustered using the same unbiased approach of batch correction as described earlier. Five clusters were observed in both groups (Figure 4 A). Cell cycle pseudotime analysis of the clusters revealed a clear distinction in the cell cycle phase of the clusters in both groups (Figure 4 B). Differential gene expression analysis of the clusters not only revealed the genes involved in quiescence and activation in both groups (Supplementary Figure S2), but also showed a marked similarity between the clusters. we found that a number of highly overexpressed genes in clusters 1 and 2 from the adult group were also highly expressed in clusters 2 and 3 in the pediatric group (Figure 4 C). while the set of clusters overexpressing a large number of ribosomal genes (RP), especially RPL23, RPL34, RPS3, RPS13, RPS29 also correlate with qGSC cells, the cGSC dominant set was marked by the overexpression of a number of high mobility group (HMG) genes including $H M G B 1$ and $H M G B 2$ and heterogeneous nuclear ribonucleoprotein (hnRNP) genes, notably HNRNPA3 and HNRNPD. Recent research points to intricate relation between ribosomal activity and quiescence in stem cells[38, 39]. Indeed, high level of ribosomal presence can block stem cell differentiation. On the other hand, while HMG and TOP2A transcription regulators represent dynamic cell division, hnRNPs are key factors in pre-mRNA processing and transport. Indeed, based on gene expression pattern and cell cycle pseudotime analysis, a picture of sequential progression between the clusters is indicated with the overexpression of ribosomal proteins positively correlating with true 
264

265

266

267

268

269

270

271

272

273

quiescence while the overexpression of HMG and hnRNPs indicating progression into cycling phase. In terms of disease model, it is likely that the mechanism of transition from quiescent to cycling states in GBMs remains similar to that of NSCs. In terms of patient samples, all patient samples from the adult group had the presence of ribosome overexpressing cluster (cluster 1), whereas in the pediatric group the ribosome overexpressing cluster (cluster 2) was absent in BT830. Similarly, the hnRNP/ HMG overexpressing cluster in the adult group (cluster 2) was absent in PJ-32 (Figure 4 D). This may be because the number of cells included in the study may not represent the total tumoral heterogeneity or that the qGSC and cGSC states are interconvertible. Cluster wise differentially expressed genes for both adult and pediatric groups are included in additional file 2 .

Gene ontology (GO) analysis of the clusters further confirmed our observations with the ribosome overexpressing cluster enriched in the biological process of cotranslational protein targeting to membrane or endoplasmic reticulum. The HMG and hnRNPs overexpressing clusters were enriched in cell cycle stages of DNA replication and sister chromatid separation. These clusters are likely representative of cycling cells from S to G2 phases. Interestingly, in the pediatric group, we found that the cluster 5 which comprised of a few cells from samples BT1160, BT-749, BT-771 and MGH-85 was enriched for neuronal development and differentiation (Figure 5 A). However, we could not determine if this subpopulation is a transformed NSC precursor of a specific lineage.

\section{Analysis of copy number variations (CNVs)}

Copy number alterations (gain and/or loss) of the DNA are known to be associated with disease progression in various cancers[40]. Based on the gene expression patterns in the qGSCs and cGSCs, we reasoned that the variations in the chromosomal regions of these cells is likely 
287 distinct from normal or differentiated neoplastic glial/neuronal cells. To confirm this hypothesis,

288 we compared the CNV status of GSC (qGSC and cGSC) clusters with non-malignant and

289 differentiated neoplastic cells. For comparison, we used the gene expression counts of 332 of

290 adult normal brain cells from dataset: GSE67835 as reference[25]. The results did not show a

291 clear similarity in CNV patterns of adult and pediatric groups, however, we did observe a pattern

292 of copy number gain at chromosomes 19 and 11 in some patients in the pediatric group (BT-

293 1160, BT-749, BT-771, MGH-85). In terms of pediatric group, we found a consistent CNV

294 pattern in the GSC population (Figure 5 B) (see also supplementary Figure S3). Chromosomes

29519 showed a copy number gain while chromosome10 showed a loss of copy number. Locus gain

296 at chromosome 19 is relevant in this study's context because Chromosome 19 which has a high

297 gene density, also harbors a large number of ribosomal genes [41]. While there seems to be a

298 correlation between copy number alteration at chromosome 19 and ribosomal protein abundance,

299 we could not verify this correlation in terms of causation. However, we consider this an

300 interesting finding, which needs to be explored in detail in the future.

301

302

303

304

305

306 


\section{DISCUSSION}

311 Glioblastomas present marked inter and intra tumoral heterogeneity which is a key hurdle in

312 identifying tumorigenic cell populations and therefore designing robust therapeutic strategies to

313 target them. Recent advances in single cell techniques has helped immensely in studying and

314 intratumoral cellular niches. However, identification of GSCs which are considered to be the

315 drivers of tumor progression and therapy resistance largely remains a challenge because they

316 exist as a small population of cycling and quiescent cells within these niches. The dynamic

317 nature of tumor microenvironment means that these cells show considerable phenotypic

318 plasticity. This behavior of GSCs would suggest that a marker based strategy, although very

319 informative in describing cellular state at a given time, is insufficient in identifying stem cell like

320 tumor populations with marked cellular plasticity. The existence of GSC-like cells in

321 proliferative and quiescent states within these niches is largely agreed upon, however, the

322 identification of quiescent GSC-like population has remained a challenge. Through our study of

323 scRNAseq data from a diverse panel GBM samples we have identified gene signature patterns

324 uniquely associated with cycling and quiescent states in GBM cells.

325 A number of single cell sequencing based studies in recent years have focused on identifying

326 GSCs $[15,18,20,22,42]$, these studies support the theory that malignancy in glioblastoma is a

327 function of a small number of progenitor like cells which may exist in neural, mesenchymal,

328 oligodendrocyte or astrocyte like states. The results of this analysis show that although most of

329 the cycling and quiescent GSCs do share similarities with endothelial and glial like cells, they

330 have unique transcriptomic profiles which suggest that these cells are maintained in their own

331 niches within the microenvironment surrounded or populated with mature endothelial, neural 
and/or glial cells. It is important to underline the observation that while transformed cells from the non-GBM tumor (GS-15) had endothelial, microglia and oligodendrocyte like populations, they lacked both cGSC and qGSC like cells. This provides evidence that glioblastoma is inherently a disease of neural stem/progenitor cells.

A number of studies on cancer stem cells have largely focused on the expression of genes related to a few key transcription factors (Yamanaka factors), OCT4, SOX2, KLF4, and MYC[43] including NANOG which are well known markers for pluripotency. Similarly, makers for proliferation like MKI67 and CD44 are the focus of most of the research on proliferating and pluripotent malignant cells in GBM. However, such approaches overlook the molecular processes involved in maintaining quiescence or triggering proliferation. Indeed, we observed no correlation between CD44 expression and cGSCs. On the other hand, our analysis gives further evidence that SOX4, SOX11 and DCX do overexpress in cycling and quiescent GSCs, however, studying these markers alone won't explain the molecular process involved in maintaining quiescence or triggering proliferation.

The results of this analysis provides strong evidence that quiescent and cycling stem like cells in GBM share common molecular pathway to maintain quiescence. By comparing the difference in the gene expression profiles of qGSC and cGSC clusters, we have been able to captures the changes in cellular processes of the cells transitioning from quiescent to cycling state. Notably, the quiescent state is underlined by the overexpression of a number of ribosomal genes while the cycling state is marked by the overexpression of HMG and hnRNPs. This switch from ribosomal gene family to HMG and hnRNP genes suggests triggering of entry into cycling phase is accompanied by profound changes in cell physiology. The presence of migration and neuronal differentiation related genes like $S 100 B$, VIM and SPARC in a quiescent like separate cluster 
(cluster 5) may show the presence of NSC like or progenitor cells. further research is required to understand their interaction with other clusters. In terms of patient groups, the results show that adult tumor samples had a much lower proportion of qGSCs, this is probably reflective of the differences in developmental state of brain. Importantly, the results suggest that qGSCs and cGSCs of NSC nature are a key feature of the glioblastoma tumor microenvironment. These populations are largely interconvertible but are maintained predominantly by the expression of genes distinct to these states.

The role of ribosomal proteins in stem cell maintenance is an area of active research[44]. Recent research on mouse NSCs has shown low protein synthesis rate as a hallmark of quiescent state[45]. This phenomenon of quiescent NSCs is probably due to reduced activity of the mTOR (mammalian target of rapamycin) kinase which acts as a key bridge linking ribosome biogenesis and protein synthesis to induction of pluripotency, self-renewal and differentiation in adult stem cells[46, 47]. Experimentally, it has been shown that knockdown of 4E-BP1 (an mTOR target) promotes differentiation in mouse NSCs[48], mTOR signaling drops when the cell exits cell cycle, leading to suppression of ribosome synthesis, controlling NSC differentiation[49]. It is thus likely that a number of ribosomal proteins are maintained in the quiescent cells to trigger differentiation, thus ensuring and effective transformation of the stem cell state upon receiving environmental signal[47, 48, 50, 51]. While this is a possible theory for the overexpression of ribosomal genes in quiescent cells, further studies are needed to understand this phenomenon in glioblastoma.

In conclusion, this study provides vital insight in the expression profile of cycling and quiescent like cells in glioblastoma. Therapy designs targeting these cells holds great promise in the treatment of GBM patients because studies have shown that these cells are key to developing 
378 therapy resistance, migration and proliferation. Targeting quiescent GSCs is critical to overcome

379 tumor relapse. This work is an important step in understanding the molecular processes that

380 govern the quiescent and cycling states in GBMs.

381

382

383

384

385

386

387

388

389

390

391

392

393

394

395

396

397 


\section{MATERIALS AND METHODS}

400

401

402

403

404

405

406

407

408

409

410

411

412

413

414

415

416

417

418

\section{Data resource and selection}

All Single-Cell RNA-Seq raw read count matrices and metadata files (wherever available) were were downloaded from Gene Expression Omnibus (GEO) repository. Specifically, gene/cell expression counts from datasets GSE84465[17],GSE117891[18],GSE131928[52] and GSE103224[19] downloaded. The expression matrix for patients included in the study was then curated from the raw expression files. Raw counts for patient data from GSE131928 was not made available by the authors. Log2 transformed count (available) was used instead.

\section{Data filtration and normalization}

All datasets were filtered and analyzed using Seurat V4[53]. Raw data matrix was first filtered using the slandered Seurat protocol to remove possible low quality cells, cells with <200 or $>3000$ transcripts were excluded from the analysis. In addition, cells of poor quality, recognized as cells with $>5 \%$ of their transcripts coming from mitochondrial genes, were excluded from the downstream analysis.

\section{Clustering techniques}

Primary clustering of the datasets was done following Seurat protocol. Briefly, after filtering and removal of mitochondrial counts, the data was log normalized and highly variable features were calculated (for this study, we kept the nfeature setting to 6000). Next, the data was scaled before performing linear dimensional reduction. High variable principal components were selected based on percentage variance. Next, the $\mathrm{K}$ nearest neighbor graph was constructed based on 
419 calculated principal components and clustered. Finally, the dimensional reduction and

420 visualization was done using Uniform Manifold Approximation and Projection (UMAP).

421

422

423

424

425

426

427

428

429

430

431

432

433

434 from further analysis.

\section{Integration of datasets}

\section{Differential gene expression analysis}

Analysis of differentially expressed genes for each clusters was done by implementing Modelbased Analysis of Single Cell Transcriptomics (MAST) package with Seurat[54].

For integrated analysis, following initial Seurat protocol, the fast mutual nearest neighbors (fastMNN) R/Bioconductor package was applied to correct for differences between data sets (batch effect correction)[55]. Clustering was done using default parameters.

\section{Reference based cell type identification}

Cell type identification was performed using singleR[56]. which is an R/Bioconductor package to perform unbiased cell type recognition from single-cell RNA sequencing data, by using reference datasets of pure cell types to identify the cell type of individual single cells independently. Here we used the dataset from Darmanis, Spyros, et al.[25] as reference dataset for cell type identification. Cells not recognized as either of the cell types (NAs) were removed

\section{Cell cycle trajectory inference}

Cell cycle phase of the integrated datasets was inferred using the Tricycle R/Bioconductor

437 package, which uses a fixed reference dataset to infer cell cycle phase of the test dataset[57]. Here, we used the reference dataset provided in tricycle with default parameters to infer cell 439 cycle positions of cells in integrated data. The inferred positions were then project on to the 
441 positions approximately relate to theta as: $0.25 \mathrm{pi}-1.75 \mathrm{pi}$ to $\mathrm{G} 0 / \mathrm{G} 1$ stage, $0.5 \mathrm{pi}$ to start of $\mathrm{S}$ stage,

442 pi to start of G2M stage and 1.5pi the middle of $\mathrm{M}$ stage.

\section{$443 \quad$ CNV analysis}

444 To compare the copy number variations between clusters and datasets, we used CONICSmat

445 (Copy-Number Analysis in Single-Cell RNA-Sequencing from an expression matrix) R package

446 which compares average gene expression of genes within a region to calculate the variance in

447 copy number across samples[58]. Although reference data is not explicitly required, yet, for

448 added certainty, we used normal brain expression matrix of 322 normal brain cells from

449 Darmanis, Spyros, et al[25]. Analysis was done following the default protocol.

\section{Gene Ontology (GO) analysis}

451 Up to 50 (wherever possible) overexpressing genes for each cluster were analyzed for the

452 enrichment of associated GO terms. Top 5 terms were selected based on fold change and

453 represented graphically.

\section{$454 \quad$ Statistical analysis}

455 All data analysis was performed with R. Specific packages used are mentioned in the above 456 sections. 


\section{FIGURE LEGENDS}

Figure 1: Identification of Immune and neural cells clusters

471 (A) UMAP representation of clusters of all datasets. Immune cells are colored yellow; neural

472 cells are colored blue, for GSE117891, blue represents transformed cluster, yellow-immune and

473 green, neuronal-like. (B) Bar plot showing cluster wise expression levels of immune cell

474 markers, bars are color coded according to the clusters in A. (C) Bar plot showing expression

475 levels of neuronal markers, bars are color coded according to clusters in A.(D) Bar plot showing

476 expression levels of EGFR, bars are colored red. All expression values are log transformed.

$477 \quad$ Figure 2: Cell type comparison of Adult and pediatric groups

478 (A) UMAP representation of Adult and Pediatric groups. Clusters are numbered and color coded.

479 (B) Violin plot of cluster wise expression distribution of cell cycle and neural cell type markers.

480 (C) UMAP representation of expression distribution of markers for quiescence, proliferation and 481 migration in adult and pediatric clusters. Color transition represents expression levels with high 482 expression represented in deep blue. All expression values are log transformed. 
Figure 3: Group wise comparison of identified cell types

484 (A) Heat map of cluster wise expression comparison of markers for cell types in adult and

485

486

487

488

489

490

491

492

493

494

495

496

497

498

499

500

501

502

503

504 pediatric groups. Cells with no strong matches are marked as NA. (B) Violin plot of top nine overexpressed genes in the cycling cells common to both adult and pediatric groups. (C) Violin plot of top eight overexpressed genes in the quiescent cells common to both adult and pediatric groups. (D) Patient sample wise composition of cell types in adult and pediatric groups. All expression values are log transformed.

Figure 4: Group wise comparison of cycling and quiescent clusters

(A) UMAP representation of integrated clustering of cycling and quiescent cells in Adult and Pediatric groups. Clusters are numbered and color coded. (B) UMAP representation of cell cycle status of the clusters from A. Theta values correspond cell cycle stages as follows: $0.25-1.75 \pi \sim$ G0/G1 stage, $0.5 \pi \sim$ start of S stage, $\pi \sim$ start of G2M stage and $1.5 \pi \sim$ middle of M stage. (C) Cluster wise composition of cycling quiescent populations in patient samples from adult and pediatric groups.

Figure 5: Pathway enrichment and copy number variations in cycling and quiescent cells

(A) Bar plots of top five biological processes enriched in cycling and quiescent clusters based on common overexpressed genes in adult and pediatric groups. log fold enrichment of biological processes is represented as bars. (B) Representative images of inferred CNVs in cycling and quiescent cells from one pediatric patient sample (BT-1160) compared to normal cells. 
514 GBM: Glioblastoma

515 GSC: Glioblastoma stem cell

516 NSC: Neural stem cell

517 UMAP: Uniform Manifold Approximation and Projection

518 cGSC: Cycling glioblastoma stem cell

519 qGSC: Quiescent glioblastoma stem cell

520 HMG: High mobility group protein

521 hnRNP: Heterogeneous nuclear ribonucleoprotein 
bioRxiv preprint doi: https://doi.org/10.1101/2021.12.09.472030; this version posted December 10, 2021. The copyright holder for this preprint (which was not certified by peer review) is the author/funder, who has granted bioRxiv a license to display the preprint in perpetuity. It is made available under aCC-BY 4.0 International license.

524

525

526

527

528

529

530

531

532

533

534

535

536

537

538

539

540

541

542 
548 Additional File 1: Group wise list of differentially expressed genes according to respective

549 clusters for Figure 2 A.

550 Additional File 2: Group wise list of differentially expressed genes and common genes according

551 to respective clusters for Figure 4.

552 Supplementary figure S1: Cell Cycle pseudotime representation of unclustered cycling and

553 quiescent GSCs from adult and pediatric groups.

554 Supplementary figure S2: Dot plot representation of top ten genes per cluster for figure 4.

555 Supplementary figure S: CNV profiles of GSCs from pediatric group patient samples. 


\section{REFERENCES}

565 1. Ferlay J, Colombet M, Soerjomataram I, Mathers C, Parkin DM, Piñeros M, et al. Estimating 566 the global cancer incidence and mortality in 2018: GLOBOCAN sources and methods. Int $\mathbf{J}$ 567 Cancer. 2019;144:1941-53.

568 2. Wesseling P, Capper D. WHO 2016 Classification of gliomas. Neuropathology and Applied 569 Neurobiology. 2018;44:139-50.

570 3. Berger K, Turowski B, Felsberg J, Malzkorn B, Reifenberger G, Steiger H-J, et al. Age-

571 stratified clinical performance and survival of patients with IDH-wildtype glioblastoma

572 homogeneously treated by radiotherapy with concomitant and maintenance temozolomide. J

573 Cancer Res Clin Oncol. 2021;147:253-62.

574 4. de Weille J. On the Genesis of Neuroblastoma and Glioma. International Journal of Brain 575 Science. 2014;2014:e217503.

576 5. Suvà ML, Tirosh I. The Glioma Stem Cell Model in the Era of Single-Cell Genomics. Cancer 577 Cell. 2020;37:630-6.

578 6. Brescia P, Ortensi B, Fornasari L, Levi D, Broggi G, Pelicci G. CD133 is essential for 579 glioblastoma stem cell maintenance. Stem Cells. 2013;31:857-69.

580 7. Beier D, Hau P, Proescholdt M, Lohmeier A, Wischhusen J, Oefner PJ, et al. CD133+ and 581 CD133- Glioblastoma-Derived Cancer Stem Cells Show Differential Growth Characteristics and 582 Molecular Profiles. Cancer Res. 2007;67:4010-5. 
583 8. Ogden AT, Waziri AE, Lochhead RA, Fusco D, Lopez K, Ellis JA, et al. Identification of 584 A2B5+CD133- tumor-initiating cells in adult human gliomas. Neurosurgery. 2008;62:505-14;

585 discussion 514-515.

586 9. Anido J, Sáez-Borderías A, Gonzàlez-Juncà A, Rodón L, Folch G, Carmona MA, et al. TGF- $\beta$

587 Receptor Inhibitors Target the CD44high/Id1high Glioma-Initiating Cell Population in Human

588 Glioblastoma. Cancer Cell. 2010;18:655-68.

589 10. Paugh BS, Zhu X, Qu C, Endersby R, Diaz AK, Zhang J, et al. Novel Oncogenic PDGFRA

590 Mutations in Pediatric High-Grade Gliomas. Cancer Res. 2013;73:6219-29.

591 11. Schultz C, Lemke N, Ge S, Golembieski WA, Rempel SA. Secreted Protein Acidic and Rich 592 in Cysteine Promotes Glioma Invasion and Delays Tumor Growth in Vivo. Cancer Res.

$593 \quad 2002 ; 62: 6270-7$.

594 12. Shmelkov SV, Butler JM, Hooper AT, Hormigo A, Kushner J, Milde T, et al. CD133

595 expression is not restricted to stem cells, and both CD133+ and CD133- metastatic colon cancer 596 cells initiate tumors. J Clin Invest. 2008;118:2111-20.

597 13. Wang J, Sakariassen PØ, Tsinkalovsky O, Immervoll H, Bøe SO, Svendsen A, et al. CD133

598 negative glioma cells form tumors in nude rats and give rise to CD133 positive cells. Int J

599 Cancer. 2008;122:761-8.

600 14. Jung E, Osswald M, Ratliff M, Dogan H, Xie R, Weil S, et al. Tumor cell plasticity, 601 heterogeneity, and resistance in crucial microenvironmental niches in glioma. Nat Commun. $602 \quad 2021 ; 12: 1014$. 
603

604

605

606

607

608

609

610

611

612

613

614

615

616

617

618

619

620

15. Suvà ML, Rheinbay E, Gillespie SM, Patel AP, Wakimoto H, Rabkin SD, et al.

Reconstructing and reprogramming the tumor propagating potential of glioblastoma stem-like cells. Cell. 2014;157:580-94.

16. Vinay DS, Ryan EP, Pawelec G, Talib WH, Stagg J, Elkord E, et al. Immune evasion in cancer: Mechanistic basis and therapeutic strategies. Seminars in Cancer Biology. 2015;35:S185-98.

17. Darmanis S, Sloan SA, Croote D, Mignardi M, Chernikova S, Samghababi P, et al. SingleCell RNA-Seq Analysis of Infiltrating Neoplastic Cells at the Migrating Front of Human Glioblastoma. Cell Rep. 2017;21:1399-410.

18. Yu K, Hu Y, Wu F, Guo Q, Qian Z, Hu W, et al. Surveying brain tumor heterogeneity by single-cell RNA-sequencing of multi-sector biopsies. Natl Sci Rev. 2020;7:1306-18.

19. Yuan J, Levitin HM, Frattini V, Bush EC, Boyett DM, Samanamud J, et al. Single-cell transcriptome analysis of lineage diversity in high-grade glioma. Genome Medicine. 2018;10:57.

20. Dirkse A, Golebiewska A, Buder T, Nazarov PV, Muller A, Poovathingal S, et al. Stem cellassociated heterogeneity in Glioblastoma results from intrinsic tumor plasticity shaped by the microenvironment. Nat Commun. 2019;10:1787.

21. Guo M, Peng Y, Gao A, Du C, Herman JG. Epigenetic heterogeneity in cancer. Biomarker Research. 2019;7:23. 
621

622

623

624

625

626

627

628

629

630

631

632

633

634

635

636

637

638

639

22. Giraddi RR, Chung C-Y, Heinz RE, Balcioglu O, Novotny M, Trejo CL, et al. Single-Cell Transcriptomes Distinguish Stem Cell State Changes and Lineage Specification Programs in Early Mammary Gland Development. Cell Rep. 2018;24:1653-1666.e7.

23. Summers KL, Hock BD, McKenzie JL, Hart DNJ. Phenotypic Characterization of Five

Dendritic Cell Subsets in Human Tonsils. Am J Pathol. 2001;159:285-95.

24. Campanelli JT, Sandrock RW, Wheatley W, Xue H, Zheng J, Liang F, et al. Expression profiling of human glial precursors. BMC Dev Biol. 2008;8:102.

25. Darmanis S, Sloan SA, Zhang Y, Enge M, Caneda C, Shuer LM, et al. A survey of human brain transcriptome diversity at the single cell level. PNAS. 2015;112:7285-90.

26. Thakurela S, Garding A, Jung J, Schübeler D, Burger L, Tiwari VK. Gene regulation and priming by topoisomerase II $\alpha$ in embryonic stem cells. Nat Commun. 2013;4:2478.

27. Kimura A, Matsuda T, Sakai A, Murao N, Nakashima K. HMGB2 expression is associated with transition from a quiescent to an activated state of adult neural stem cells. Dev Dyn. 2018;247:229-38.

28. Rehli M, Niller H-H, Ammon C, Langmann S, Schwarzfischer L, Andreesen R, et al. Transcriptional regulation of $\mathrm{CHI} 3 \mathrm{~L} 1$, a marker gene for late stages of macrophage differentiation. J Biol Chem. 2003;278:44058-67.

29. Li S, Wei X, He J, Tian X, Yuan S, Sun L. Plasminogen activator inhibitor-1 in cancer research. Biomedicine \& Pharmacotherapy. 2018;105:83-94. 
640 30. Li L, Clevers H. Coexistence of Quiescent and Active Adult Stem Cells in Mammals.

641 Science. 2010;327:542-5.

642

643

644

645

646

647

648

649

650

651

652

653

654

655

656

657

658

659

31. Wang H-H, Liao C-C, Chow N-H, Huang LL-H, Chuang J-I, Wei K-C, et al. Whether CD44 is an applicable marker for glioma stem cells. Am J Transl Res. 2017;9:4785-806.

32. Codega P, Silva-Vargas V, Paul A, Maldonado-Soto AR, DeLeo AM, Pastrana E, et al.

Prospective Identification and Purification of Quiescent Adult Neural Stem Cells from Their In Vivo Niche. Neuron. 2014;82:545-59.

33. Pauklin S, Vallier L. The Cell-Cycle State of Stem Cells Determines Cell Fate Propensity. Cell. 2013;155:135-47.

34. White J, Dalton S. Cell cycle control of embryonic stem cells. Stem Cell Rev. 2005;1:131-8.

35. Cheshier SH, Morrison SJ, Liao X, Weissman IL. In vivo proliferation and cell cycle kinetics of long-term self-renewing hematopoietic stem cells. PNAS. 1999;96:3120-5.

36. Bradley E, Bieberich E, Mivechi NF, Tangpisuthipongsa D, Wang G. Regulation of embryonic stem cell pluripotency by heat shock protein 90. Stem Cells. 2012;30:1624-33.

37. Han Y, Wang X. The emerging roles of KPNA2 in cancer. Life Sciences. 2020;241:117140.

38. Sharifi S, da Costa HFR, Bierhoff $\mathrm{H}$. The circuitry between ribosome biogenesis and translation in stem cell function and ageing. Mechanisms of Ageing and Development. 2020;189:111282.

39. van Velthoven CTJ, Rando TA. Stem Cell Quiescence: Dynamism, Restraint, and Cellular Idling. Cell Stem Cell. 2019;24:213-25. 
40. Shlien A, Malkin D. Copy number variations and cancer. Genome Med. 2009;1:62.

661

662

663

664

665

666

667

668

669

670

671

672

673

674

675

676

677

678

41. Kenmochi N, Kawaguchi T, Rozen S, Davis E, Goodman N, Hudson TJ, et al. A map of 75

human ribosomal protein genes. Genome Res. 1998;8:509-23.

42. Pang B, Xu J, Hu J, Guo F, Wan L, Cheng M, et al. Single-cell RNA-seq reveals the invasive trajectory and molecular cascades underlying glioblastoma progression. Mol Oncol.

2019;13:2588-603.

43. Liu X, Huang J, Chen T, Wang Y, Xin S, Li J, et al. Yamanaka factors critically regulate the developmental signaling network in mouse embryonic stem cells. Cell Res. 2008;18:1177-89.

44. Sanchez CG, Teixeira FK, Czech B, Preall JB, Zamparini AL, Seifert JRK, et al. Regulation of Ribosome Biogenesis and Protein Synthesis Controls Germline Stem Cell Differentiation. Cell Stem Cell. 2016;18:276-90.

45. Urbán N, van den Berg DLC, Forget A, Andersen J, Demmers JAA, Hunt C, et al. Return to quiescence of mouse neural stem cells by degradation of a proactivation protein. Science. 2016;353:292-5.

46. Rodgers JT, King KY, Brett JO, Cromie MJ, Charville GW, Maguire KK, et al. mTORC1 controls the adaptive transition of quiescent stem cells from G0 to GAlert. Nature. 2014;510:393-6.

47. Gan B, DePinho R. mTORC1 signaling governs hematopoietic stem cell quiescence. Cell Cycle. 2009;8:1003-6. 
679 48. Guo J, Zhang T, Guo Y, Sun T, Li H, Zhang X, et al. Oocyte stage-specific effects of MTOR 680 determine granulosa cell fate and oocyte quality in mice. PNAS. 2018;115:E5326-33.

681

682

683

684

685

686

687

688

689

690

691

692

693

694

695

696

49. mTORC1 controls the adaptive transition of quiescent stem cells from G0 to GAlert | Nature. https://www.nature.com/articles/nature13255. Accessed 9 Dec 2021.

50. Zhang Q, Shalaby NA, Buszczak M. Changes in rRNA transcription influence proliferation and cell fate within a stem cell lineage. Science. 2014;343:298-301.

51. Blair JD, Hockemeyer D, Doudna JA, Bateup HS, Floor SN. Widespread Translational Remodeling during Human Neuronal Differentiation. Cell Rep. 2017;21:2005-16.

52. Neftel C, Laffy J, Filbin MG, Hara T, Shore ME, Rahme GJ, et al. An Integrative Model of Cellular States, Plasticity, and Genetics for Glioblastoma. Cell. 2019;178:835-849.e21.

53. Hao Y, Hao S, Andersen-Nissen E, Mauck WM, Zheng S, Butler A, et al. Integrated analysis of multimodal single-cell data. Cell. 2021;184:3573-3587.e29.

54. Finak G, McDavid A, Yajima M, Deng J, Gersuk V, Shalek AK, et al. MAST: a flexible statistical framework for assessing transcriptional changes and characterizing heterogeneity in single-cell RNA sequencing data. Genome Biology. 2015;16:278.

55. Haghverdi L, Lun ATL, Morgan MD, Marioni JC. Batch effects in single-cell RNAsequencing data are corrected by matching mutual nearest neighbors. Nat Biotechnol. 2018;36:421-7. 
697 56. Aran D, Looney AP, Liu L, Wu E, Fong V, Hsu A, et al. Reference-based analysis of lung 698 single-cell sequencing reveals a transitional profibrotic macrophage. Nat Immunol.

$699 \quad 2019 ; 20: 163-72$.

700 57. Zheng SC, Stein-O’Brien G, Augustin JJ, Slosberg J, Carosso GA, Winer B, et al. Universal 701 prediction of cell cycle position using transfer learning. 2021.

702 58. Müller S, Cho A, Liu SJ, Lim DA, Diaz A. CONICS integrates scRNA-seq with DNA 703 sequencing to map gene expression to tumor sub-clones. Bioinformatics. 2018;34:3217-9. 
Figure 1

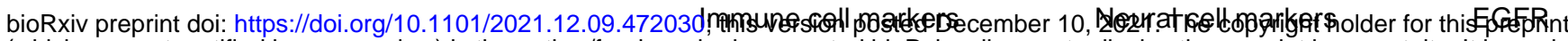
A (which was not certified by peer review) is the author/funder, who has granted bioRxiv a license to display the preprint in perpetuity. It is made

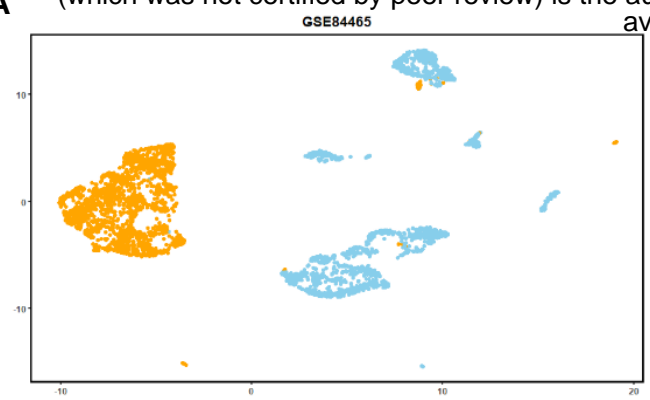

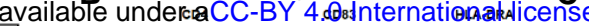
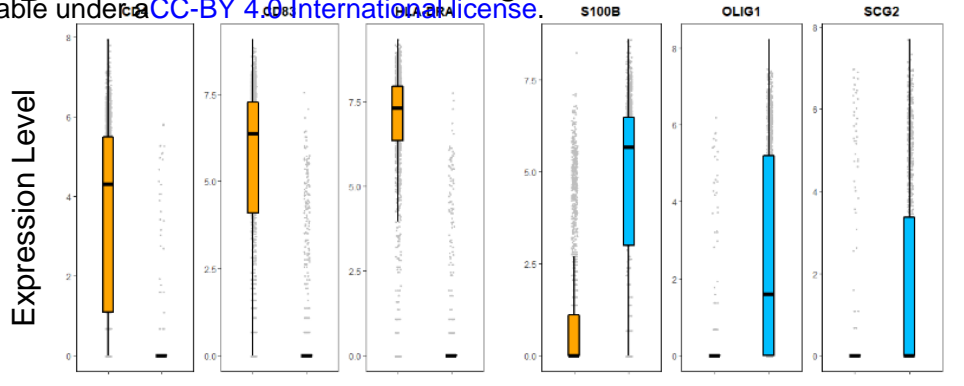
EGFR
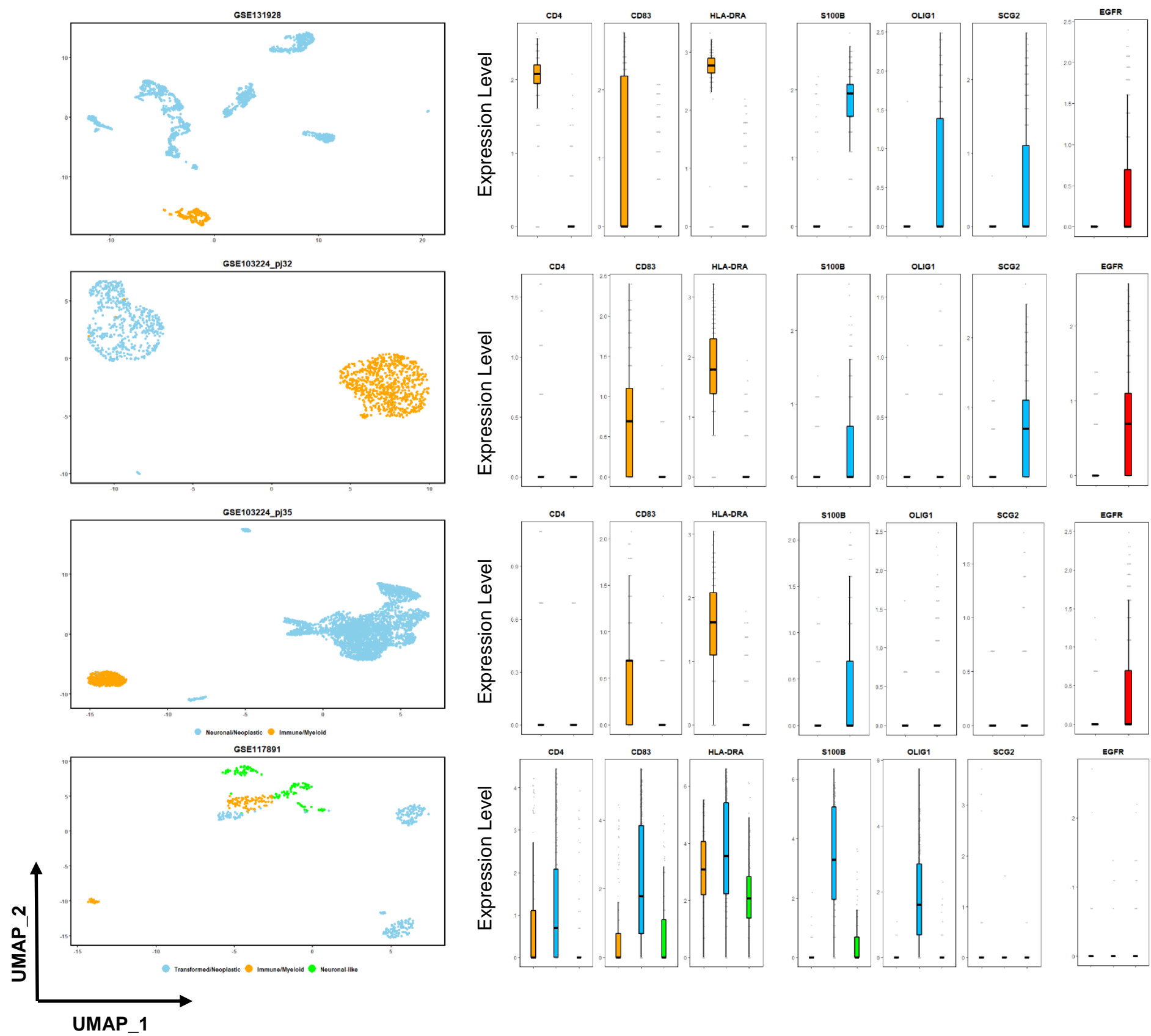

UMAP_1 
Figure 2

A

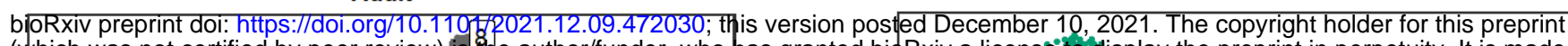
(which was not certified by peer review) is one author/funder, who has granted bioRxiv a licenseito display the preprint in perpetuity. It is made
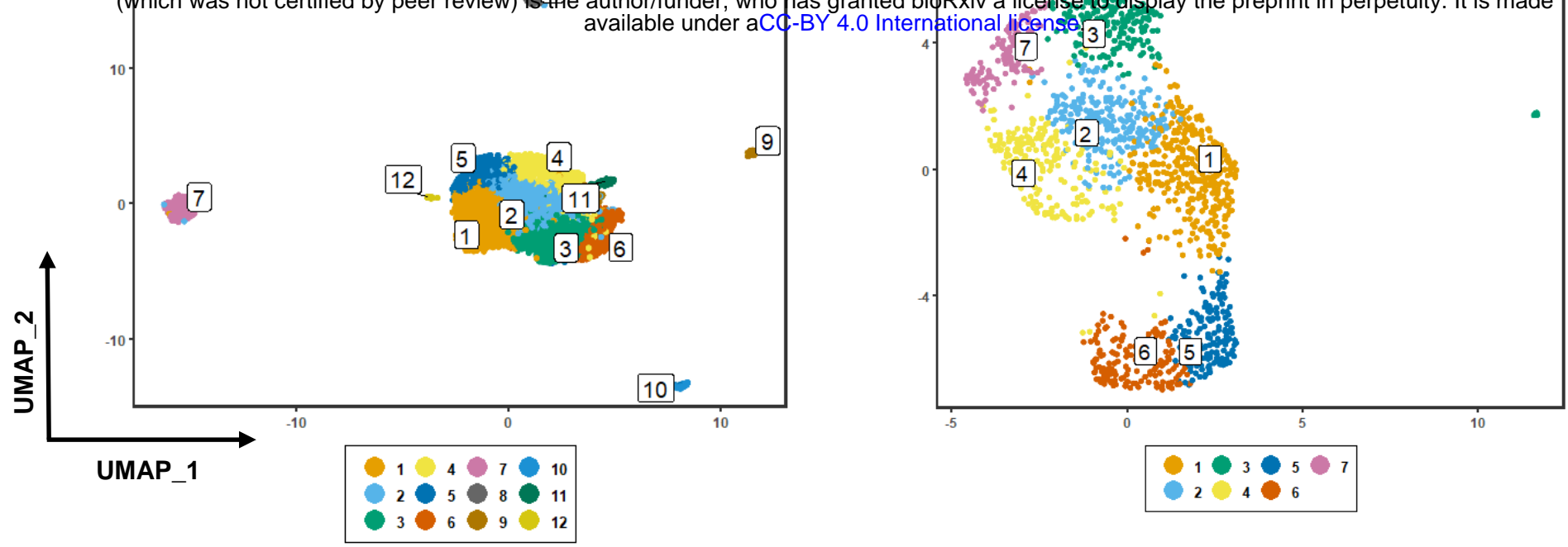

B
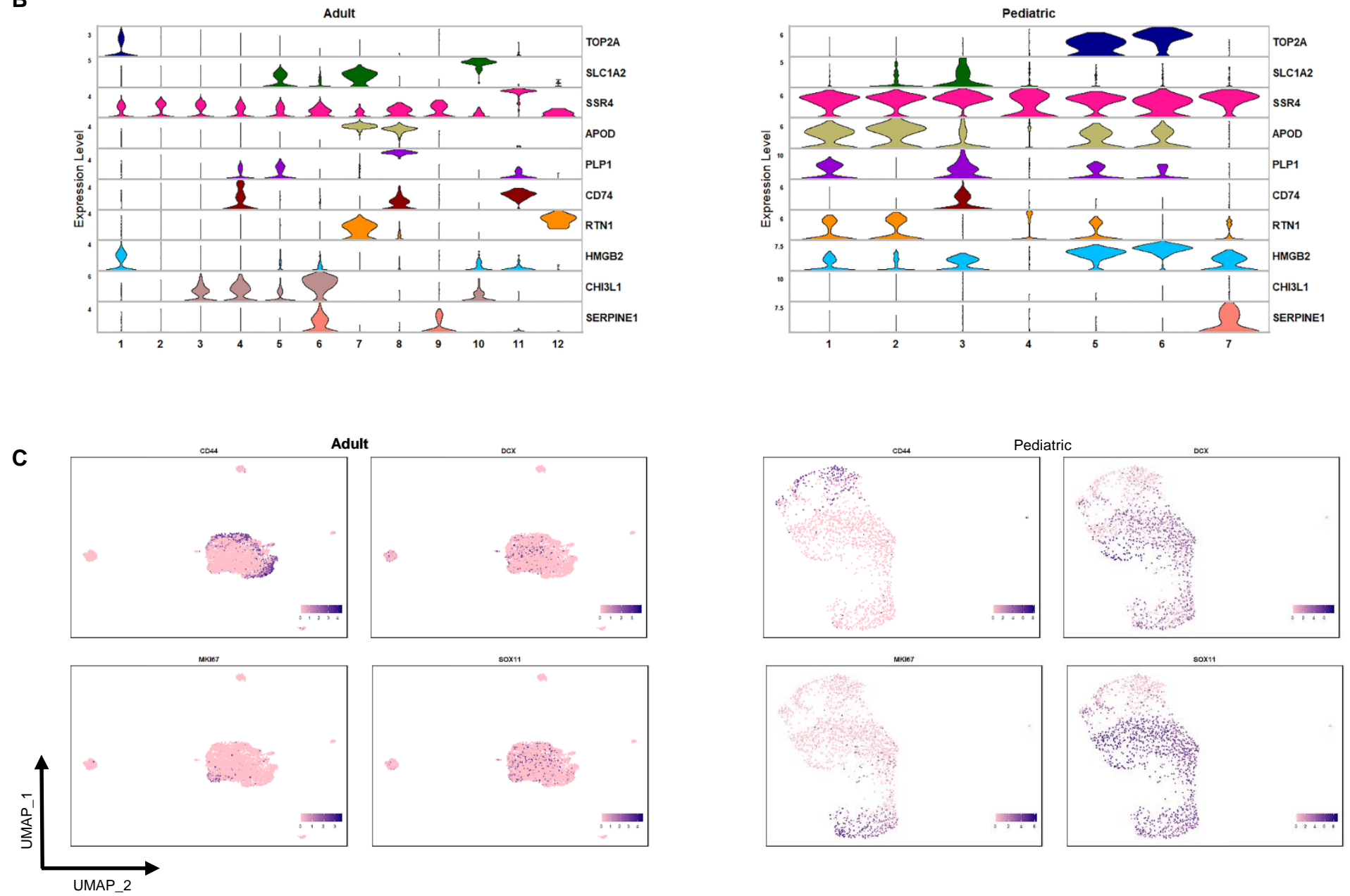


\section{Figure 3}

bioRxiv preprint doi: httpsAldullot.org/10.1101/2021.12.09.472030; this version posted December Pleapettridhe copyright holder for this preprint (which was not certified by peen review) is the author/funder, who has granted bioRxiva lieense to display the preprint in perpetuity. It is made

A

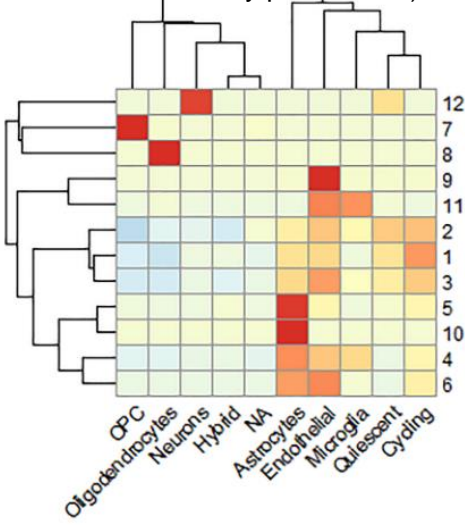

B

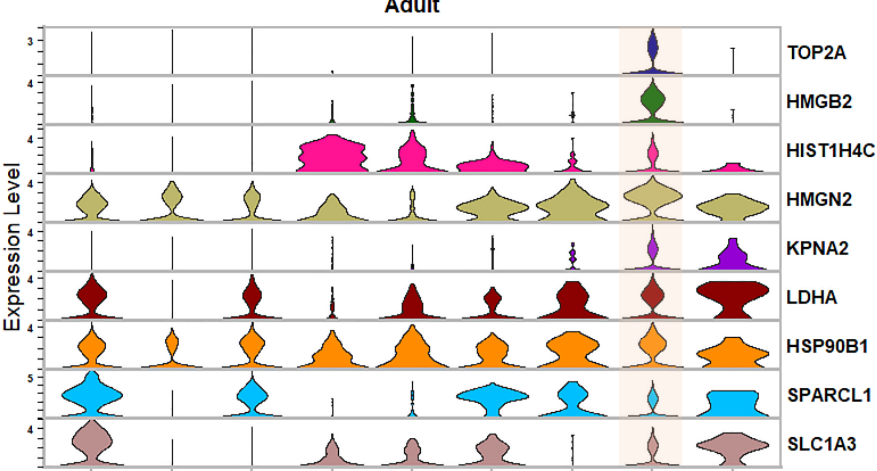

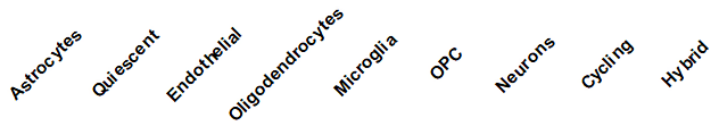

C

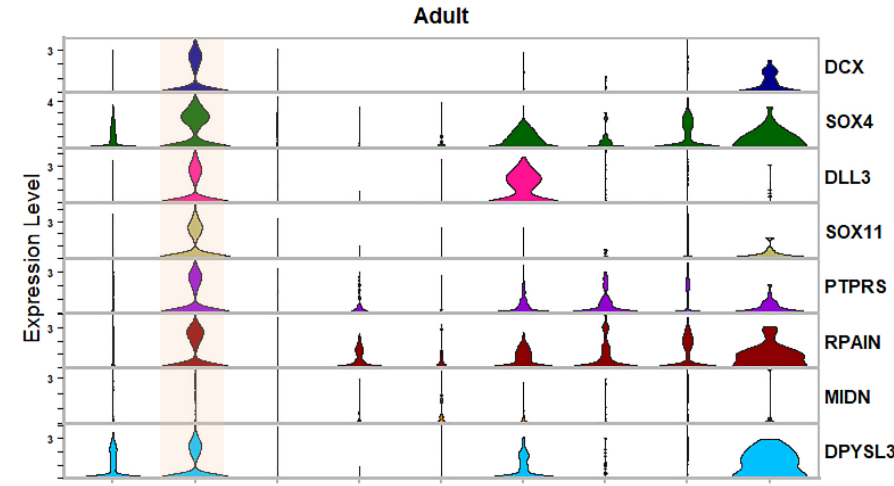

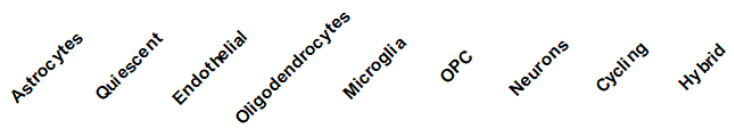

D

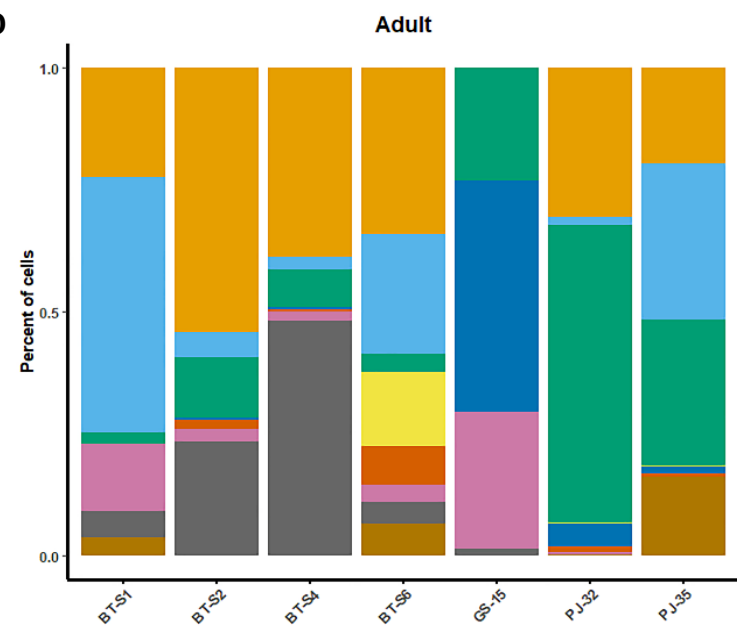

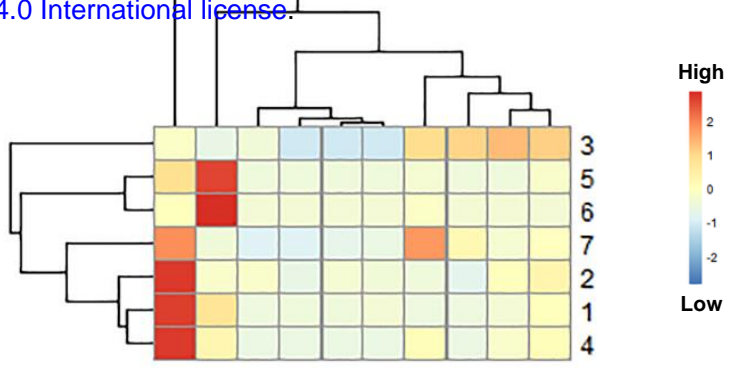

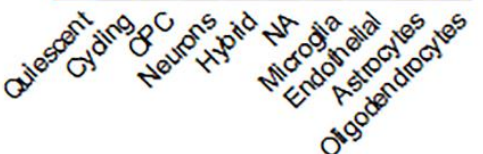

Pediatric

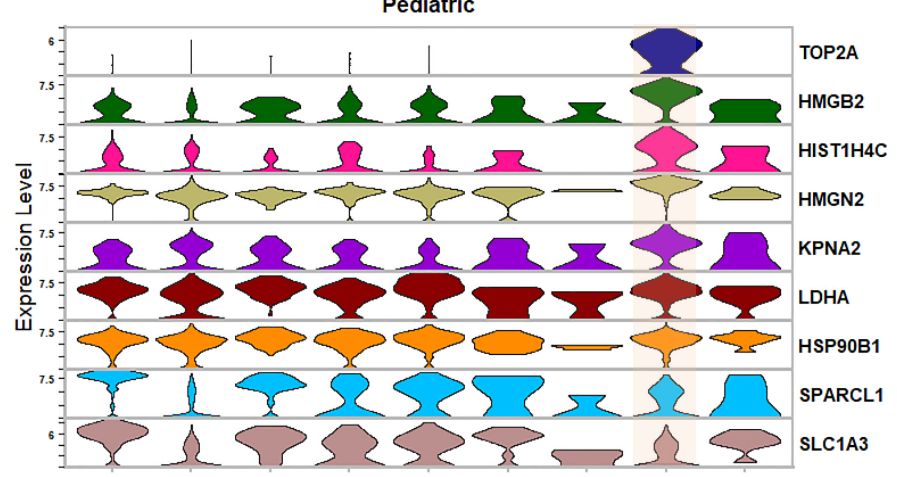

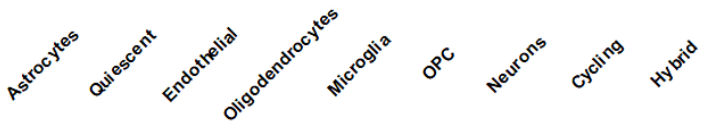

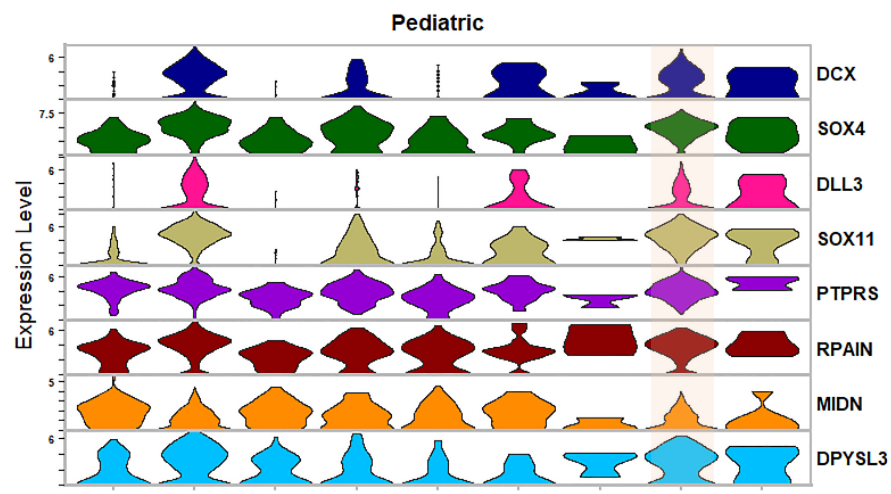

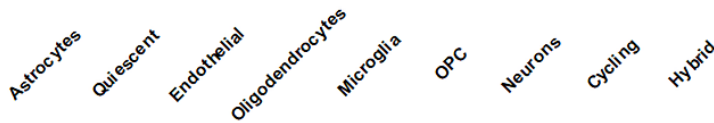

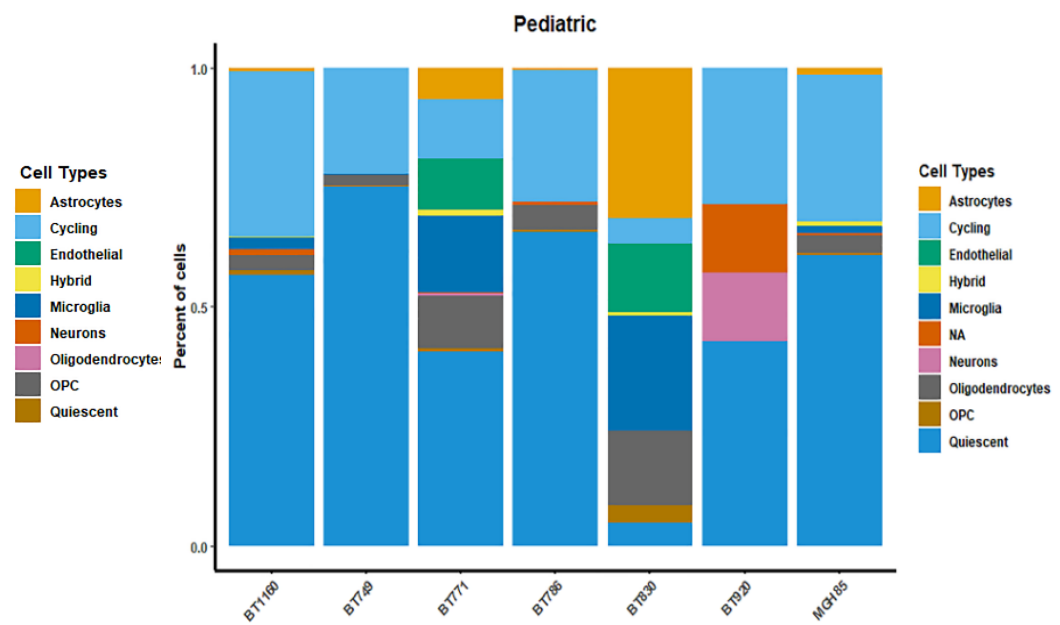




\section{Figure 4}

A

bioRxiv preprint doi: httrand/doi.org/10.1101/2021.12.09.472030; this version posted Decemater 10, 2021. The copyright holder for this preprint (which was not certified by peer review) is the authrg/funder, who has granted bioRxiv a ticense to display the preprimtin perpetuity. It is made

B
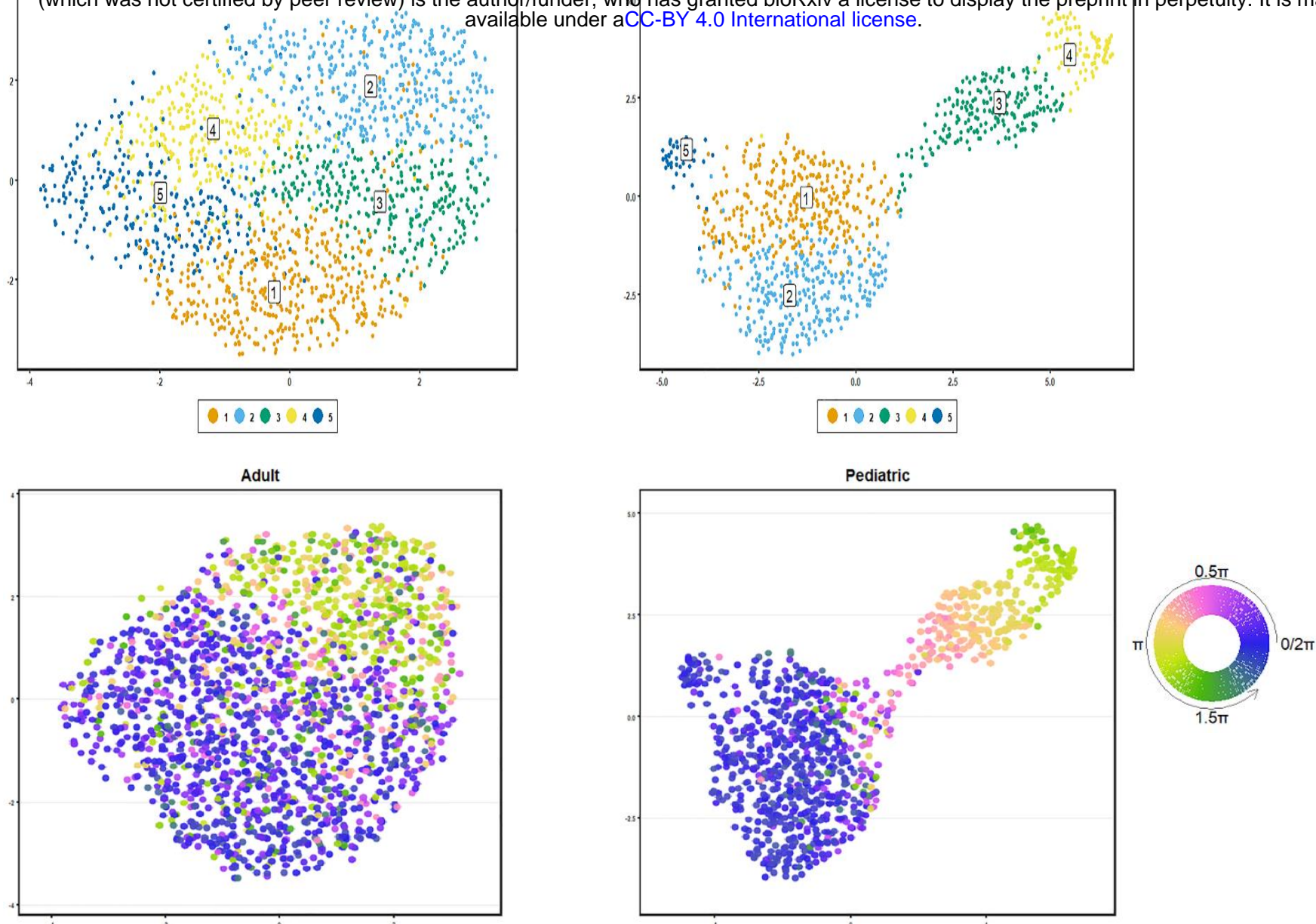

C
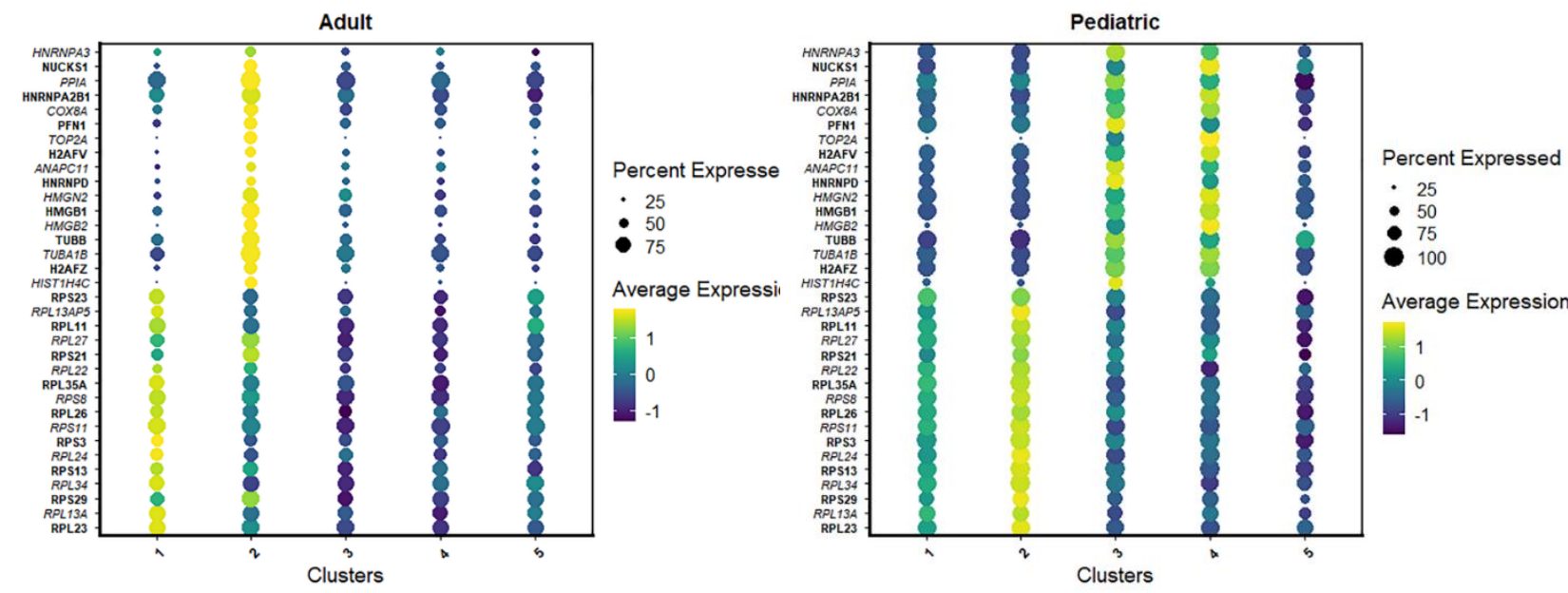

D
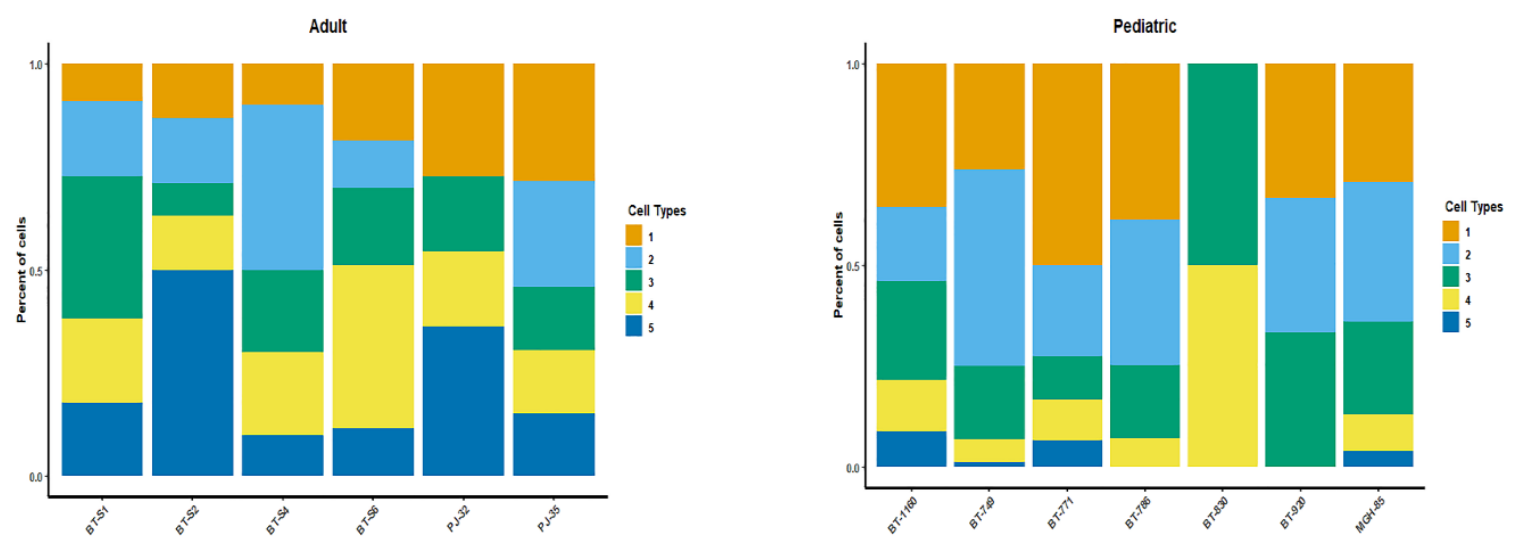


\section{Figure 5}

AioRxiv preprint doi: https://doi.org/10.1101/2021.12.09.472030; this version posted December 10, 2021. The copyright holder for this preprint (which was not certified by peer review) is the author/funder, who has granted bioRxiv a license to display the preprint in perpetuity. It is made

qGSC Clusters

Cytoplasmic translation

lo endoplasmic reticulum

Protein targeting to ER

Cotranslational protein targeting to membrane

RP.dependent cotranslational protein targeting to membrane available under aCC-BY 4.0 International license.
cGSC clusters

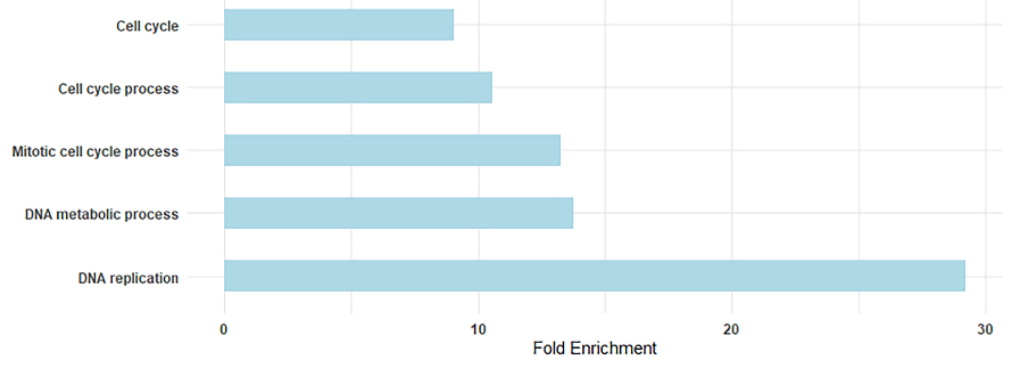

NSC- Precursor like Cluster

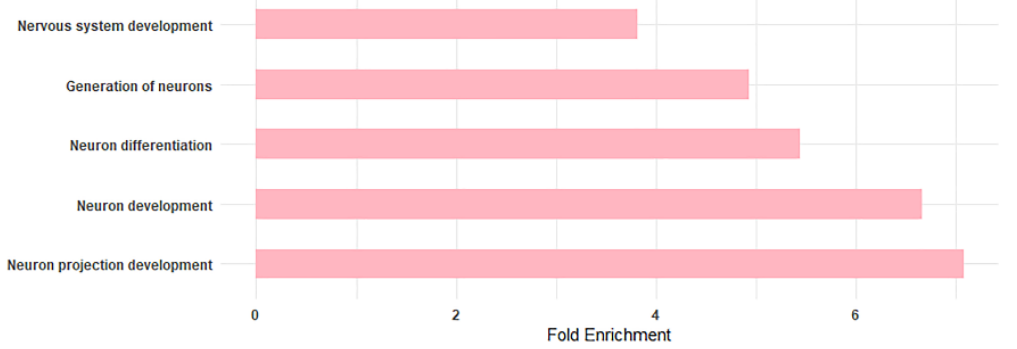

B

Normal

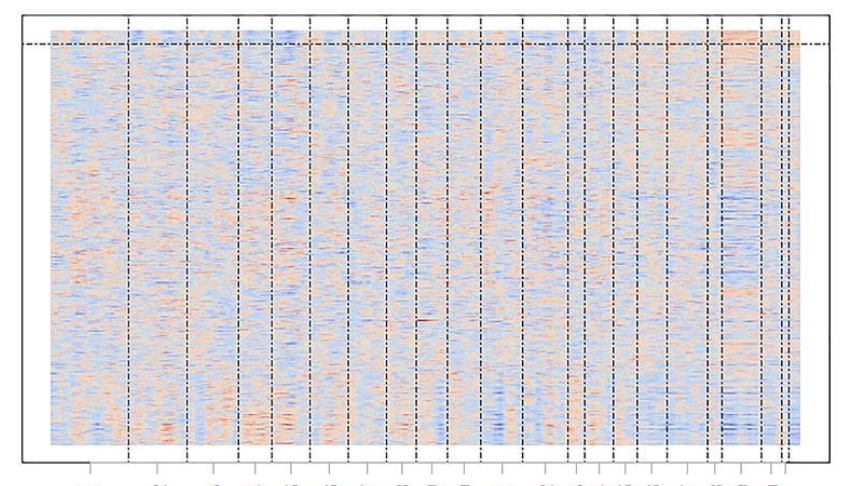

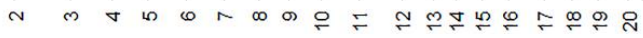

BT-1160

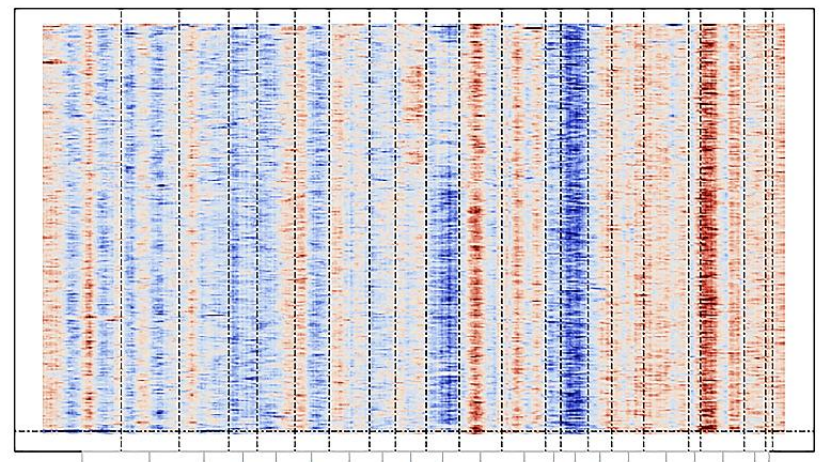

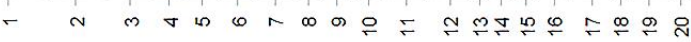

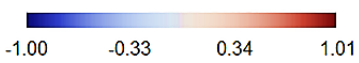

